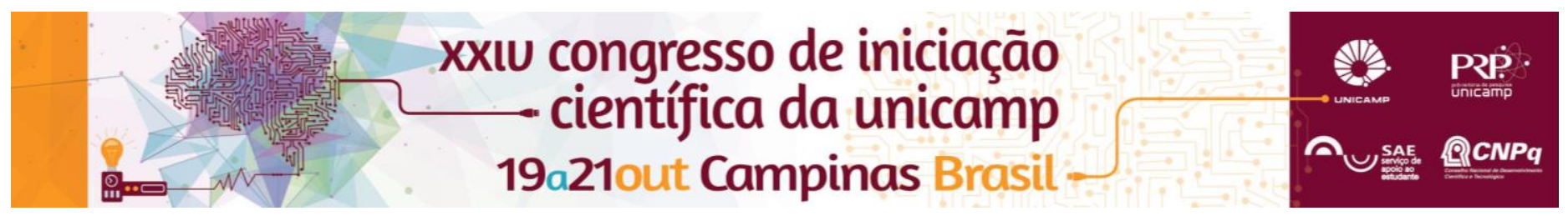

\title{
A hidrologia do município de Mogi Guaçu/SP sob impacto dos resíduos sólidos
}

\author{
Ramon Vilela*, Thiago A. A. Reis, Antoniane A. O. Roque, Rogério M. Santos.
}

\section{Resumo}

Considerando a necessidade do município de Mogi Guaçu/SP de ter um mapeamento das áreas com maior impacto de resíduos sólidos sobre a hidrologia local, o presente trabalho particiona o município em microbacias hidrográficas de maneira que seja possível quantificar as atuais áreas de risco. Utilizando softwares de geoprocessamento SIG e dados do NIMA, NASA, IBGE, LUPA e CATI, foi possível chegar em resultados expressivos demonstrados no trabalho.

\section{Palavras-chave}

Hidrologia, MDE, SIG.

\section{Introdução}

A geração de resíduos vem se tornado um problema em escala global, e os recursos hídricos são importantes indicadores das condições do ecossistema ${ }^{1}$, sendo assim, a utilização combinada de dados morfométricos e ferramentas de geoprocessamento SIG para a delimitação de áreas e suas características, pode ser um instrumento útil para planejamentos urbanos ${ }^{2}$.

Com base em análises espaciais juntamente com informações como as do censo agrícola do IBGE e dados do LUPA, é possível delimitar áreas prioritárias em relação a produção de resíduos que supostamente tendem a contribuir nas microbacias.

\section{Resultados e Discussão}

Obtendo-se os dados das bases vetoriais do $\operatorname{INDE}^{3}$ e o MDE obtido pela SRTM $^{4}$ que foram aplicados nos softwares de geoprocessamento, foi possível modelar a rede de drenagem e áreas edificadas de Mogi Guaçu, conforme Figura 1.

Figura 1. MDE de Mogi Guaçu com rede de drenagem e áreas edificadas.

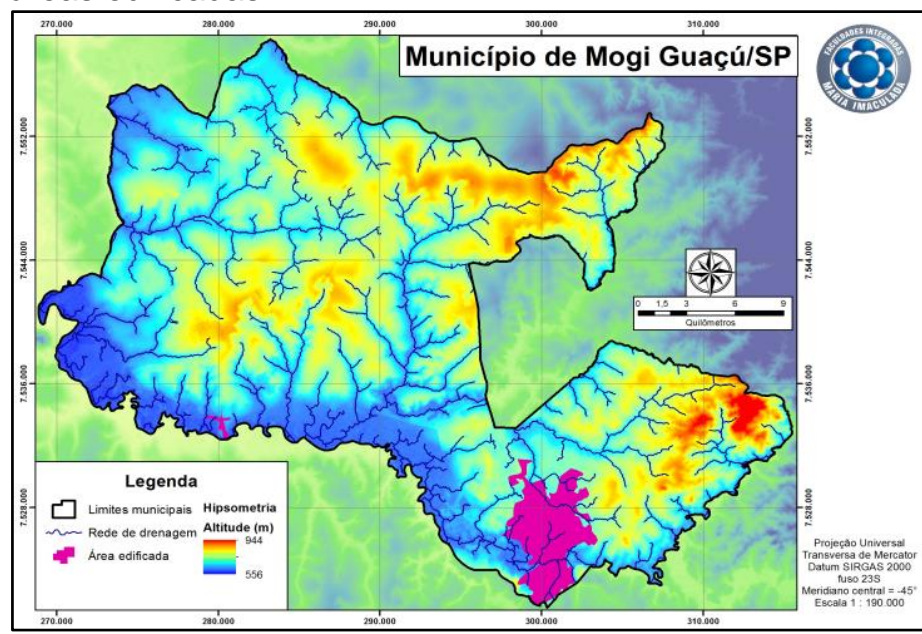

A Figura 2 delimita as microbacias geradas para a rede de drenagem de Mogi Guaçu com destaque para as microbacias críticas sob o enfoque de despejo de resíduos sólidos.

A Tabela 1 mostra os resultados mais relevantes obtidos pelo trabalho.
Figura 1. Microbacias de Mogi Guaçu.

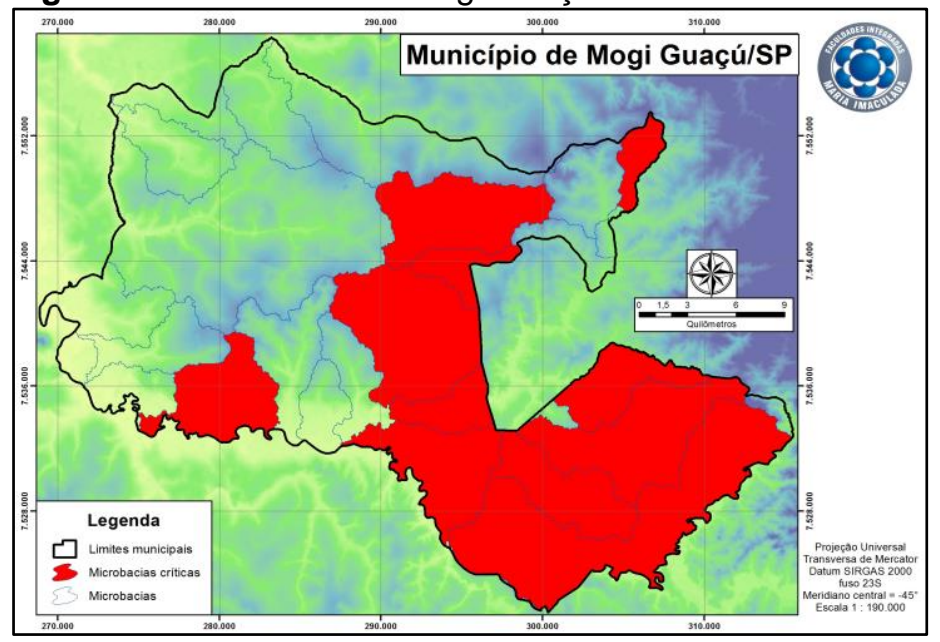

Tabela 1. Resultados obtidos.

\begin{aligned} & \hline Rede de drenagem $701,98 \mathrm{~km} \\ &$\hline Microbacias hidrográficas 34 \\ & \hline Produção de resíduos $122,15{\mathrm{ton} . \text { dia }^{-1}}^{-1} \\ &$\hline Área de maior impacto de resíduos $399,50 \mathrm{~km}^{2} \\ &$\hline Porcentagem de área de risco $50,78 \% \\ &$\hline Rede de drenagem em áreas críticas $356,43 \mathrm{~km} \\ &$\hline\end{aligned}

\section{Conclusões}

Como o conceito de bacia hidrológica vem sendo muito utilizado como fator de planejamento ambiental, as análises a partir de ferramentas SIG podem ser de grande auxílio a programas de gestão sustentável de resíduos no município de Mogi Guaçu, com foco de priorização das áreas determinadas como de risco.

${ }^{1}$ ANTONELI, V; THOMAZ, E.L. Caracterização do meio físico da bacia do Arroio Boa Vista, Guamiranga-PR. Rev. Caminhos da Geografia, Uberlândia, v. 8, n.21, p46-58, jun. 2007

${ }^{2}$ CÂMARA, G. et al. Territórios Digitais: As Novas Fronteiras do Brasil. Seminário Temático Preparatório para a $3^{\mathrm{a}} \mathrm{CNCTI}$. Centro de Gestão e Estudos Estratégicos. Ciência, Tecnlogia e Informação. 2005. Disponível em < www.dpi.inpe.br/gilberto/present/territorios_digitais.ppt >. Acesso em: jul. 2014.

${ }^{3}$ INDE. Visualizador da INDE. http://www.visualizador.inde.gov.br/. Acesso em jan. 2015

${ }^{4}$ NASA (2015). Shuttle Radar Topography Mission (SRTM) 1 Arc-Second Global. http://earthexplorer.usgs.gov/. Acesso em jan. 2015. 